\title{
Comparison of total blood loss between volatile agents and total intravenous anesthesia for posterior spinal fusion in adolescents with idiopathic scoliosis
}

\author{
$\underline{\text { Yagmur Ateser R. }}{ }^{1}$, Kayabası ${ }^{2}{ }^{2}$,Yanık H.S. ${ }^{3}$, Subası F.D. ${ }^{1}$, Batan S. ${ }^{1}$, Ekinci O. ${ }^{1}$, Bekiroglu G.N.. ${ }^{4}$ \\ ${ }^{1}$ Haydarpaşa Numune Training and Research Hospital, Dept of Anaesthesiology \& Intensive Care, Istanbul, Turkey, ${ }^{2}$ Haydarpaşa Numune \\ Training and Research Hospital, Dept of Nephrology, Istanbul, Turkey, ${ }^{3}$ Haydarpaşa Numune Training and Research Hospital, Dept. of \\ Orthopedics and Traumatology Surgery, Istanbul, Turkey, ${ }^{4}$ Marmara University School of Medicine, Dept. of Biostatistics, Istanbul,
}

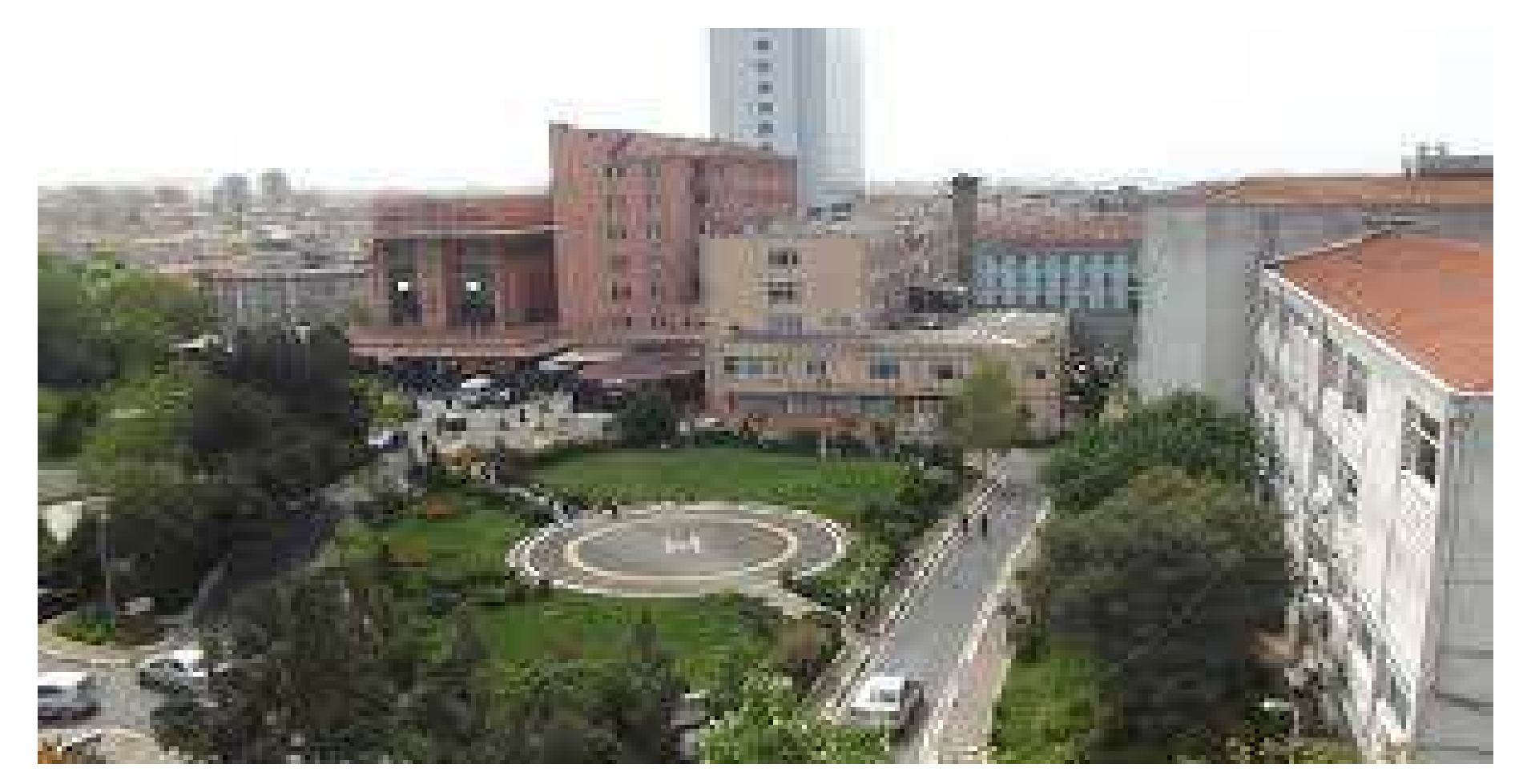

Background and Goal of Study: The purpose of this study was to prospectively compare the amount of total blood loss( intraoperatively and postoperative) during general anesthesia with either a total intravenous technique or with the volatile anesthetic agent in scoliosis surgery. According to our knowledge, there are no studies about anesthesia techniques and their effects on blood loss in scoliosis surgery

Materials and Methods: Patients with 18-65 ages, ASA (I-III) and scheduled for elective all segmental pedicle screw and posterior enstrumantation surgery (long fusion>10 levels) were included into the study. Patients were randomly allocated to the general anesthesia groups with either a total intravenous technique(TIVA) $(n=17)$ or with the volatile anesthetic agent (VA) $(n=11)$, desflurane. Total blood loss $(\mathrm{ml})$ (intraoperatively and postoperative $12 \mathrm{hr}, 24 \mathrm{hr}$ and $48 \mathrm{hr}$ ), hemodynamic variables (Arterial blood pressure, SPO2, Heart rate ) laboratory values ( Hemoglobin,Hemotocrit , Bleeding time ,postoperatively $12 \mathrm{hr}, 24 \mathrm{hr}, 48 \mathrm{hr}$ ) and amount of red blood cell transfusion (unit) were used to compare between two groups. Unpaired t-test and correlaton coefficient was calculated between two variables in each group. $\mathrm{P}<0.05$ was considered as significant
Results and Discussion: The age and duration of surgery for the patients in TIVA and VA groups were found respectively as (20-40yrs) and (18-43yrs); (47,6hrs) and (4-6,5hrs). There was no statistically significant difference between groups for the duration of surgery, spinal fusion level, hemodynamic variables and laboratory values in both groups. Although the amount of intraoperative blood loss, and intraoperative and postoperative blood transfusions were found statististically insignificant $(p=0,098, p=0,909$, $\mathrm{p}=0,580$ ), there was a slight decrasing tendency in TIVA group $(600,00 \pm 355,43 \mathrm{ml}, \quad 1,57 \pm 0,65 \quad$ units, $2,47 \pm 0,87$ units $)$ than the VA group $(8836,36 \pm 345,75 \mathrm{ml}$,

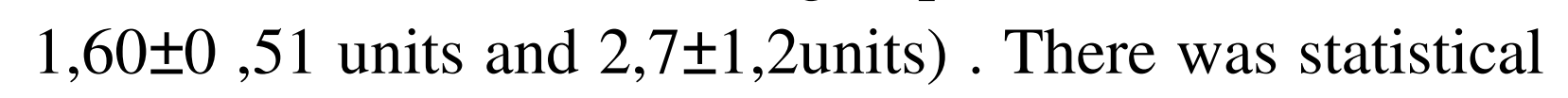
significant difference between groups for blood loss at $12 \mathrm{hr}$ which is less for TIVA group $(303,23 \pm 87,44 \mathrm{ml})$ when compared with VA group $(410 \pm 143,17 \mathrm{ml}(\mathrm{p}<0.05)$.

Conclusion: Our data demonstrate that a total intravenous technique is better than the volatile anesthetic agent group regarding the amount of intraoperative and postoperative blood loss, but we could not find significant mean difference with intraoperative blood loss 